\title{
Conhecimentos pedagógicos na formação de professores: uma análise do manual "Pedagogia e Prática Docente" (2012)
}

\section{Pedagogical knowledge in teacher education: an analysis of the "Pedagogy and Teaching Practice" manual (2012)}

\section{Conocimientos pedagógicos en la formación del profesorado: un análisis del manual "Pedagogía y Práctica Docente" (2012)}

\author{
Léia de Cassia Fernandes Hegeto ${ }^{1}$ \\ Tiago Cordeiro dos Reis ${ }^{1}$
}

DOI: http://dx.doi.org/10.20435/serie-estudos.v26i57.1424

\begin{abstract}
Resumo: Este artigo tem como objetivo analisar os conhecimentos pedagógicos presentes na formação de professores a partir da análise do manual "Pedagogia e Prática Docente", da autora Maria Amélia R. S. Franco (2012). Os manuais são produtos e produtores de conhecimentos e práticas escolares (BUFREM; SCHMIDT; GARCIA, 2006), sendo também construtores de identidades pessoais e profissionais docentes. A pesquisa qualitativa teve como fundamento a análise documental e a análise de conteúdo (BARDIN, 2011) para revelar os conhecimentos abordados no manual, o qual faz parte da Coleção Docência em Formação/Série Saberes Pedagógicos, da Editora Cortez. Foram selecionadas as seguintes categorias de análise: temáticas e encaminhamento metodológico presentes no livro. Foram analisadas as temáticas: Pedagogia, Didática, Práticas Educativas, Práticas Pedagógicas, Práticas Docentes, Subjetividade Pedagógica e Dialogicidade; e a pesquisa-ação como encaminhamento metodológico. Os resultados revelam que o livro analisado trata sobre os conhecimentos mobilizados no ato de ensinar e os desafios da Pedagogia e Prática Docente, contribuindo, assim, para a formação de professores. O livro propõe uma metodologia de pesquisa pedagogicamente fundamentada para uso dos docentes nas práticas escolares coletivas.
\end{abstract}

Palavras-chave: conhecimentos pedagógicos; manuais; formação de professores.

Abstract: This article aims to analyze the pedagogical knowledge present in teacher training based on the analysis of the manual "Pedagogy and Teaching Practice" (free translation), by author Maria Amélia R. S. Franco (2012). Manuals are products and producers of school knowledge and practices (BUFREM; SCHMIDT; GARCIA, 2006), and are also builders of personal identities and teaching professionals. The qualitative research was based on document analysis and content 
analysis (BARDIN, 2011) to reveal the knowledge covered in the manual, which is part of Editora Cortez's Coleção Docência em Formação/Série Saberes Pedagógicos. The following categories of analysis were selected: themes and methodological guidance present in the book. The themes were analyzed: Pedagogy, Didactics, Educational Practices, Pedagogical Practices, Teaching Practices, Pedagogical Subjectivity and Dialogicity; and action research as a methodological approach. The results reveal that the analyzed book deals with the knowledge mobilized in the act of teaching and the challenges of Pedagogy and Teaching Practice, thus contributing to the training of teachers. The book proposes a pedagogically based research methodology for use by teachers in collective school practices.

Keywords: pedagogical knowledge; didactic manuals; teacher education.

Resumen: Este artículo tiene como objetivo analizar el conocimiento pedagógico presente en la formación del profesorado basado en el análisis del manual "Pedagogía y práctica docente" (traducción libre), de la autora Maria Amélia R. S. Franco (2012). Los manuales son productos y productores de conocimiento y prácticas escolares (BUFREM; SCHMIDT; GARCIA, 2006), y también son constructores de identidades personales y profesionales de la enseñanza. La investigación cualitativa se basó en el análisis de documentos y el análisis de contenido (BARDIN, 2011) para revelar el conocimiento cubierto en el manual, que forma parte de la Coleção Docência em Formação/Série Saberes Pedagógicos, de la Editora Cortez. Fueron seleccionadas las siguientes categorías de análisis: temas y orientación metodológica presentes en el libro. Los temas analizados fueron: pedagogía, didáctica, prácticas educativas, prácticas pedagógicas, prácticas docentes, subjetividad pedagógica y dialogicidad; y la pesquisa-acción como enfoque metodológico. Los resultados revelan que el libro analizado aborda el conocimiento movilizado en el acto de enseñar y los desafíos de la práctica pedagógica y pedagógica, contribuyendo así a la formación de los docentes. El libro propone una metodología de investigación con base pedagógica para el uso de los maestros en las prácticas escolares colectivas.

Palabras clave: conocimientos pedagógicos; manuales; formación del profesorado.

\section{INTRODUÇÃO}

Com este estudo, pretende-se evidenciar o papel dos manuais pedagógicos na formação e prática docente. Defende-se a perspectiva reflexiva, pois, de acordo com Shön (1992), é imprescindível a existência concomitante entre conhecimento teórico e prático durante o processo de formação inicial e continuada. Pode-se afirmar que há uma busca pela relação teoria e prática nas discussões e leituras voltadas a professores.

A pesquisa visa contribuir com as discussões sobre manuais pedagógicos e leituras para professores e tem como objetivo geral analisar os conhecimentos pedagógicos difundidos no livro "Pedagogia e Prática Docente", da autora Maria Amélia R. S. Franco. Este livro faz parte da Série Saberes Pedagógicos e foi publicado 
pela Editora Cortez, em 2012. A série compõe a Coleção Docência em Formação e foi criada para auxiliar os licenciandos e docentes em atuação, oferecendo "[...] livros de referência para sua preparação científica, técnica e pedagógica" (PIMENTA, 2012, p. 11).

A justificativa da pesquisa pauta-se na existência de lacunas nas pesquisas que analisam os conhecimentos pedagógicos presentes em livros atuais voltados à formação de professores. Há uma quantidade significativa de pesquisas sobre manuais pedagógicos e leituras para professores publicados no período de 1930 a 1971 (SILVA, 2003). Outra justificativa para a realização dessas pesquisas é por acreditar que os manuais, sendo reveladores dos modos de pensar e organizar a formação de professores em cada período, podem revelar características da Pedagogia nesses últimos anos, contribuindo, assim, com as pesquisas científicas e educacionais na área pedagógica.

A partir da década de 1980, percebe-se uma mudança nas características e no foco dos manuais pedagógicos em forma de coletâneas, quando os livros passam a ser escritos por vários autores com diferentes perspectivas e enfoques. Constata-se também que os livros voltados à formação de professores tratam de novas temáticas e abarcam discussões curriculares considerando o contexto político e social do Brasil. Os autores, a partir de uma perspectiva crítica, incorporam novas tendências e defesas. Os encontros nacionais de educação acabam também impulsionando os debates sobre o papel da educação, didática e pedagogia na promoção da justiça social. A escolha do Manual/livro "Pedagogia e Prática Docente" está amparada na defesa de que um manual ou livro pedagógico pode evidenciar os saberes pedagógicos considerados fundamentais para a escola e para a educação, a partir do ano de 2010.

O manual/livro "Pedagogia e Prática Docente" foi selecionado com base no número de edições, entre os anos 2012 e 2018, e pelo número de exemplares vendidos, que foi de 3.787 exemplares. Este número de vendas indica a circulação deste livro entre professores e alunos em cursos de formação. De acordo com a Editora Cortez, foram vendidas aproximadamente 550 cópias do material a cada ano.

Para chegar à escolha desse livro, foi realizado inicialmente um levantamento bibliográfico, a ser detalhado na metodologia da pesquisa. O levantamento bibliográfico contribuiu para a seleção e catalogação de livros e pesquisas cien- 
tíficas sobre manuais pedagógicos. Neste texto, será apresentada a revisão de literatura, os procedimentos metodológicos e os principais resultados.

\section{OS MANUAIS VOLTADOS À FORMAÇÃO DE PROFESSORES COMO UM ELEMENTO ORIENTADOR DA PRÁTICA}

As pesquisas na linha da história da leitura e das edições permitem compreender como os saberes educacionais foram produzidos e circulados, como também a utilização que os escritores de manuais pedagógicos fizeram da bibliografia utilizada e o entendimento das práticas relacionadas com a produção e divulgação das obras citadas por eles (CHARTIER, 1991). Portanto são inúmeras as formas de utilizar os manuais, destacando-se o uso deles como objetos de estudos históricos, fontes para análises de conteúdo e nas pesquisas em campos disciplinares e de conhecimento para investigar as suas tendências (BUFREM; SCHMIDT; GARCIA, 2006).

Na análise de um manual, é fundamental observar o contexto da bibliografia utilizada por um autor de manual e o contexto da sua produção, articulando-os com os conhecimentos apresentados no livro, a fim de compreender as suas relações (SILVA, 2003). Conforme a autora, esta postura permite a verificação das mudanças que ocorrem no processo de passagem de um conhecimento para outro e selecionar o que é essencial para a cultura profissional docente no decorrer do tempo. Já o estudo dos títulos e índices dos manuais possibilitam destacar os temas priorizados nos livros (SILVA, 2003).

Neste estudo, o termo "manuais pedagógicos" se refere a livros e leituras destinados à formação inicial e continuada de professores no âmbito da Didática Geral, ou seja, direcionados ao ensino de todas as disciplinas. Na pesquisa, compreende-se como manuais pedagógicos os livros que possuem as funções de colocar ordem nos conhecimentos necessários para a formação de professores, estabelecem de que forma os saberes devem ser transmitidos e assimilados e contribuem para a concepção da identidade docente (SILVA, 2003).

Os manuais constituem formas de fazer e de construir a educação, produzindo identidades profissionais e pessoais, referenciando e normatizando práticas pedagógicas (BUFREM; SCHMIDT; GARCIA, 2006). As leituras propostas em um manual visam explicar as práticas escolares e legitimar as práticas docentes, ao mesmo tempo em que buscam conciliar as práticas vigentes e as propostas de 
inovações pedagógicas (VALDEMARIN, 2006).

Durante a elaboração deste tipo de livro, os autores de manuais se apropriam de ideologias e preconceitos em função do seu contexto cultural. Segundo Silva (2003), os autores selecionam apenas o "essencial" da bibliografia que utilizam para elaborar os manuais; ou seja, inspiram-se em ideias de outros manuais e livros. A seleção do "essencial" para a prática docente implica a síntese do que é "ideal" para a profissão, o que, por sua vez, confere autoridade para ensinar aquilo que foi legitimado como importante (SILVA, 2003).

Esse "ideal" para a profissão trata-se de conhecimentos construídos em determinadas configurações históricas. Segundo Silva e Catani (2019), em certos períodos os manuais voltaram-se à divulgação da ciência, enquanto em outros momentos a Pedagogia como ciência da educação foi o tema desses livros. No decorrer do tempo, os manuais veicularam metáforas e comparações que ensinam a ensinar, fazendo circular nos cursos de formação saberes fundamentais ao magistério (SILVA; CATANI, 2019).

As autoras analisaram manuais publicados entre os anos de 1873 e 1909 e levantaram as concepções de Pedagogia, educação, professor, aluno e conhecimento escolar por eles difundidas. Em momentos posteriores, como no caso dos manuais produzidos entre 1940 e 1970, essas obras "[...] enfatizaram métodos didáticos e privilegiaram a explicação de como planejar aulas, ordenar os conteúdos, usar técnicas de ensino ou avaliar o rendimento dos alunos" (GARCIA; SILVA, 2019, p. 145), visando a uma formação de professores mais prescritiva. De acordo com as autoras, dos anos 1980 até os dias atuais, os manuais destinados à formação de professores ganharam destaque e diversidade, especialmente no campo da Didática enquanto disciplina escolar, abarcando também conhecimentos da Pedagogia e de outras disciplinas para a formação docente.

[...] unidos pelo propósito comum de formar futuros professores, os manuais pedagógicos vêm assumindo formas e conteúdos variados, evidenciando uma riqueza de informações, especialmente quando surgem interrogações sobre os modos pelos quais os professores vêm sendo formados e quais são os seus conhecimentos. O que trazem as páginas dos manuais pedagógicos? Lições de como proceder em aula? Explicações sobre a natureza da criança? Recomendações de como proceder corretamente na escola? (GARCIA, SILVA, 2019, p. 137). 
O conceito de formação de professores presente nos manuais decorre dos conhecimentos que eles reúnem sobre a profissão. Embora exista uma ampla produção de manuais no último século e meio, esses materiais têm em comum o objetivo de formar professores (GARCIA; SILVA, 2019). Essas autoras apontam que, com a Lei de Diretrizes e Bases da Educação Nacional (LDBEN) em 1996, ganhou força a ideia de aproximar universidade e escola básica, com a valorização dos conhecimentos da experiência nos espaços de formação docente. Segundo elas,

Tem-se, então, novas perspectivas em relação aos conhecimentos necessários ao exercício da docência. Se por um lado mantêm-se em circulação algumas ideias que podem ser encontradas em manuais antigos - embora com ares renovados - centradas na prescrição de modelos e procedimentos técnicos, por outro lado constata-se a circulação de conceitos como professor reflexivo, professor pesquisador e pesquisa em colaboração, cujos campos conceituais, também sujeitos a questionamentos e debates, situam a figura do professor em espaços de maior autonomia e de maior qualificação na produção do conhecimento sobre o ensino. (GARCIA; SILVA, 2019, p. 152).

Diante do exposto, observa-se que os manuais pedagógicos podem ser utilizados nos cursos de formação de professores, porque trazem concepções de Didática, Pedagogia, Educação. O livro "Pedagogia e Prática Docente", considerando a época em que foi produzido, pode revelar temáticas e orientações difundidas na formação de professores, ou seja, os conhecimentos legitimados e considerados essenciais nesse período, a partir da perspectiva da autora.

\section{ASPECTOS METODOLÓGICOS DA PESQUISA}

A pesquisa qualitativa ocorreu no âmbito de um projeto de iniciação científica que tem como foco o aprofundamento dos estudos sobre manuais e leituras para professores. O projeto foi realizado no Setor de Educação da Universidade Federal do Paraná, nos anos de 2018 e 2019. A pesquisa teve como ponto de partida o levantamento de obras, análise documental e a análise de conteúdo. $\mathrm{Na}$ análise documental, os documentos, no caso os manuais/livros pedagógicos, são fontes consistentes de informações e conteúdos, constituindo-se como uma rica fonte de dados e de novas interpretações (LÜDKE; ANDRÉ, 2013).

Anteriormente à seleção do manual "Pedagogia e Prática Docente", foi realizado um levantamento de manuais e artigos publicados na última década. Nesse levantamento, foram contemplados dois tipos de documentos: (1) livros 
destinados à formação de professores publicados de 2010 a 2018; (2) as publicações acadêmicas, artigos de periódicos, dissertações de mestrado e teses de doutorado, no período de 2000 a 2018.

O levantamento de trabalhos acadêmicos e artigos de periódicos derivou de uma busca nas seguintes bases de dados: Biblioteca Digital de Teses e Dissertações do Sistema de Bibliotecas da UFPR; acervo do Thesaurus Brasileiro da Educação (Brased); Catálogo de Teses e Dissertações da CAPES; e Google Scholar.

$\mathrm{Na}$ busca, foram utilizadas as palavras-chave e os descritores: manuais, manuais pedagógicos, manuais didáticos, manuais de didática, manuais para professores, manuais de ensino, ensinar a ensinar, texto para professores e manuais de formação. Inicialmente, o levantamento contemplou as publicações de 2010 a 2018. Mas, diante da escassez de resultados, a busca foi estendida.

Foram encontradas quinze pesquisas acadêmicas, dentre essas, artigos de periódicos, dissertações de mestrado e teses de doutorado. Treze pesquisas correspondem ao que Choppin (2004) categorizou como pesquisas que utilizam o manual como documento histórico e analisam seus conteúdos, tendo em vista distintas finalidades, como: investigar a história de um tema ou matéria, analisar o percurso de uma disciplina, estudar a história de diferentes modalidades de ensino.

O levantamento de manuais pedagógicos consistiu na procura de livros no acervo digital de livrarias virtuais e de bibliotecas acadêmicas. Consideraram-se apenas os livros produzidos por pesquisadores brasileiros e voltados à reflexão e orientação do trabalho docente. Na busca, foram selecionados livros/manuais que abordam a Didática Geral, isto é, que ensinam a ensinar qualquer disciplina e não tratam de temas específicos, como o uso de tecnologia ou a aplicação de um método de ensino específico a uma área ou disciplina.

A partir do levantamento de livros, foi selecionada a obra "Pedagogia e Prática Docente" (FRANCO, 2012) para análise documental, a fim de explicitar os conteúdos pedagógicos e encaminhamentos metodológicos propostos. Para a análise, foram utilizados os procedimentos propostos por Bardin (2011): a pré-análise, a exploração do material e a interpretação/inferência/tratamento dos resultados.

Para Choppin (2004), é possível utilizar a análise de conteúdo em uma perspectiva epistemológica e didática. Buscou-se compreender quais são as concepções que autores de manuais difundem acerca de uma disciplina ou campo de conhecimento, os saberes privilegiados e sua organização e os métodos de 
aprendizagem que os manuais apresentam.

Na pré-análise, foi realizada a leitura flutuante do material, com a intenção de reconhecer características gerais do material a ser analisado (BARDIN, 2011). Delimitou-se um corpus de análise, isto é, "[...] o conjunto dos documentos tidos em conta para serem submetidos aos procedimentos analíticos" (BARDIN, 2011, p. 126).

O corpus delimitado correspondeu aos trechos do livro "Pedagogia e Prática Docente" que deixam explícitos conceitos, propostas e concepções de ensino que fundamentam as reflexões e práticas na formação inicial e continuada de docentes. Após a pré-análise do manual, pautou-se nas primeiras impressões oriundas da leitura flutuante e nos objetivos da investigação. O corpus delimitado correspondeu aos trechos do livro "Pedagogia e Prática Docente" que explicitam conceitos, propostas e concepções de ensino que subsidiam as reflexões e práticas na formação inicial e continuada de docentes.

A hipótese principal está intimamente relacionada com o problema de pesquisa e o estudo da importância dos manuais, e pode ser assim enunciada: o livro "Pedagogia e Prática Docente", como um manual pedagógico, possui conhecimentos e orientações a docentes e futuros docentes em uma perspectiva reflexiva que articula teoria e prática (SHÖN, 1992).

A partir da hipótese, os índices foram estabelecidos segundo os conceitos e as temáticas identificados durante a leitura flutuante. Os índices devem ser organizados sistematicamente em um indicador, que é a frequência com que o tema (índice) aparece, seja de forma relativa, seja de forma absoluta (BARDIN, 2011).

Neste trabalho, foi escolhido o indicador de presença (ou ausência) dos índices estabelecidos no corpus em análise. Esta escolha está justificada na observação conclusiva de Bardin (2011) acerca da abordagem qualitativa. A autora aponta que:

[...] o que caracteriza a análise qualitativa é o fato de "a inferência- sempre que é realizada - ser fundada na presença do índice (tema, palavra, personagem etc!), e não sobre a frequência da sua aparição, em cada comunicação individual. (BARDIN, 2011, p. 146).

Os dados obtidos na análise do livro "Pedagogia e Prática Docente" foram categorizados em temáticas e encaminhamento metodológico e são apresentados na seção a seguir. 


\section{RESULTADOS E DISCUSSÃO DOS DADOS}

A análise do livro permitiu destacar sete temáticas e um encaminhamento metodológico proposto no manual analisado. As temáticas apresentadas são: Pedagogia; Didática; Práticas Pedagógicas; Práticas Educativas; Práticas Docentes; Subjetividade Pedagógica; e Dialogicidade. Essas temáticas são consideradas conhecimentos pedagógicos na pesquisa, uma vez que propõem reflexões sobre a prática docente.

No quadro 1 abaixo, podem ser evidenciados alguns dos significados atribuídos pela autora a cada temática:

Quadro 1 - Conhecimentos pedagógicos presentes no livro "Pedagogia e Prática Docente"

\begin{tabular}{|c|c|}
\hline Temática & Significados atribuídos pela autora \\
\hline Pedagogia & $\begin{array}{l}\text { É uma prática social e ciência que organiza, compreende, } \\
\text { transforma, fundamenta e dialoga com a prática docente. }\end{array}$ \\
\hline Didática & $\begin{array}{l}\text { Relaciona-se com o planejamento do ensino, as práticas } \\
\text { pedagógicas e a aprendizagem de conhecimentos pelos alunos. }\end{array}$ \\
\hline $\begin{array}{l}\text { Práticas } \\
\text { Educativas }\end{array}$ & $\begin{array}{l}\text { Concretizam processos educativos. Podem ser entendidas como } \\
\text { práticas sociais, ao adquirirem intencionalidade e objetivos } \\
\text { explícitos. }\end{array}$ \\
\hline $\begin{array}{l}\text { Práticas } \\
\text { Pedagógicas }\end{array}$ & $\begin{array}{l}\text { Concretizam processos pedagógicos. Visam conscientizar, } \\
\text { mobilizar e repensar as práticas docentes. }\end{array}$ \\
\hline $\begin{array}{l}\text { Práticas } \\
\text { Docentes }\end{array}$ & $\begin{array}{l}\text { Referem-se às ações dos professores. São as práticas que } \\
\text { adquirem intencionalidade e consciência do docente quanto às } \\
\text { suas ações. }\end{array}$ \\
\hline $\begin{array}{l}\text { Subjetividade } \\
\text { Pedagógica }\end{array}$ & $\begin{array}{l}\text { Está relacionada ao pensamento pedagógico brasileiro. Busca } \\
\text { compreender como as práticas pedagógicas interpretaram-no } \\
\text { historicamente. }\end{array}$ \\
\hline Dialogicidade & $\begin{array}{l}\text { É o princípio do diálogo no ensino. Teve como primeiro } \\
\text { representante histórico Sócrates e, na atualidade, Paulo Freire, no } \\
\text { Brasil. }\end{array}$ \\
\hline Pesquisa-Ação & $\begin{array}{l}\text { É o encaminhamento metodológico proposto pela autora para } \\
\text { transformar a prática docente. É abordada como instrumento, } \\
\text { metodologia de pesquisa e prática pedagógica. }\end{array}$ \\
\hline
\end{tabular}

Fonte: Os próprios autores 


\subsection{Temática Pedagogia}

A primeira temática abordada no livro pela autora é sobre a Pedagogia, considerada no livro como uma prática social cujo objetivo é organizar, compreender e transformar as práticas educativas. Nesta perspectiva, Franco (2012) considera a pedagogia como um instrumento político, porque atua no coletivo direcionando sentidos.

O que é, afinal, a Pedagogia? Antes de constituir-se como ciência, ela se estabelece como uma prática social para organizar a educação em determinado tempo e espaço, refletindo sobre suas finalidades e meios mais adequados, buscando a cada momento compreender e transformar as práticas educativas, de forma que atinjam as finalidades estabelecidas. (FRANCO, 2012, p. 48 , grifo nosso).

Franco (2012) utilizou os pressupostos de cinco pedagogos contemporâneos para demarcar sua perspectiva sobre a Pedagogia. O primeiro pressuposto vem de Dermeval Saviani, que elaborou uma teoria pedagógica crítica, a Pedagogia Histórico-Crítica (PHC), articulada ao materialismo histórico. A autora enfatiza a concepção da PHC enquanto teoria estruturada nas exigências práticas e direciona suas discussões para a construção de uma consciência coletiva, voltada à transformação da realidade.

O segundo pedagogo que fundamenta o pensamento de Franco (2012) é José Carlos Libâneo e a Pedagogia Crítico-Social dos Conteúdos (PCSC), também construída a partir do materialismo histórico-dialético. A autora destaca que Libâneo parte de uma pedagogia marxista, a qual "[...] concebe a Pedagogia como ciência da educação que descreve e explica o fenômeno educativo nos seus vínculos e nexos com a práxis social de humanização e, como ciência prática para a educação" (FRANCO, 2012, p. 98).

A autora Selma Garrido Pimenta é citada por Franco (2012) como referencial para refletir sobre a formação docente a partir da significação da prática com base na Pedagogia. Essa autora estabelece que a pedagogia é uma "[...] ciência que pode e deve fundamentar a prática, não com receitas ou teorias prontas; olha-a como a ciência que dialoga com a prática docente e extrai desse diálogo os princípios de sua ação" (FRANCO, 2012, p. 111-12).

Franco (2012) também expõe que a Pedagogia é um instrumento de intervenção social, utilizando como referencial Bernard Charlot. De acordo com a 
autora, a teoria da relação com o saber de Charlot permite que o pesquisador compreenda a lógica por trás dos sentidos construídos pelos jovens estudantes de classe popular, afastando-se das pesquisas que analisam o fracasso escolar com base nas carências socioeconômicas. Para Franco (2012, p. 119), "[...] mais que um conceito, a relação com o saber é uma metodologia, uma pedagogia, uma hermenêutica da prática".

A autora completa seus pressupostos teóricos com as ideias de Philippe Meirieu acerca de uma Pedagogia que não atua de forma prescritiva e impositiva, porém de forma reflexiva, interativa e dialógica. Segundo Franco (2012, p. 137), a pedagogia de Meirieu tem como característica a tensão entre teoria e prática, em um processo de "[...] busca incessante de meios para fundamentar o processo de ensino, o empenho por decisões cada vez mais adequadas às situações concretas".

Com base nos pensamentos desses pedagogos, Franco (2012) vai tecendo seus argumentos para convencer os leitores de que a pesquisa-ação é uma metodologia capaz de articular a Pedagogia e a Prática. Cerca de um terço do livro é dedicado aos pedagogos contemporâneos, o que evidencia a importância deles para a obra de Franco. É nítida a tentativa de destacar o "essencial" dos autores que utiliza como referência.

\subsection{Temática Didática}

A segunda temática identificada na análise foi a Didática. No livro, Franco (2012) não estabelece diretamente um conceito de Didática. Contudo é possível apontar qual é o significado atribuído pela autora com base nas funções e nas relações estabelecidas entre as práticas pedagógicas e a Didática.

A autora constrói ao longo das páginas a ideia de que a Didática se relaciona com o planejamento do ensino, com as práticas pedagógicas e aprendizagem de conhecimento pelos alunos, destacado no início do capítulo 3:

Neste capítulo, quero discutir a questão das práticas pedagógicas, tendo como pano de fundo das reflexões a questão central da Didática. Qual seria ela? Na realidade, tal questão ainda está vinculada à grande pergunta e proposta de Comenius: como ensinar tudo a todos? Não nos esqueçamos de que a lógica da Didática é a produção de aprendizagem (nos alunos) mediante processos de ensino previamente planejados. (FRANCO, 2012, p. 149, grifo nosso). 
A Didática está relacionada com o planejamento do ensino, consistindo em uma prática de intervenção e de diálogo entre os espaços dentro e fora da sala de aula. Para Franco (2012), esta prática (a Didática) deve estar fundamentada nas práticas pedagógicas.

O conceito de Didática também é construído a partir dos pressupostos dos pedagogos contemporâneos. A teoria pedagógica de Saviani conduziu Franco (2012, p. 87) a questionar: "Como transformar uma pedagogia em didática? [...] o que a Pedagogia tem a dizer à prática docente?". Nas ideias do autor Libâneo, a autora encontra reflexões sobre o papel dos conhecimentos da Didática, que é auxiliar o docente na organização dos conteúdos mediante planejamento, com o propósito de promover a aprendizagem entre os estudantes de forma contextualizada.

Uma autora citada no manual é Pimenta, que tem sua trajetória marcada pelos estudos em Pedagogia e Didática. Em relação às ideias propostas por Pimenta, Franco (2012, p. 103) afirma que "[...] é sempre a questão da teoria e da prática que a instiga a pensar e produzir. A Pedagogia fundamentando a Didática, vista como teoria do ensino, e a Didática oferecendo à Pedagogia o manancial que fundamentará a teoria desta". Para Pimenta, a Didática fornece os meios para que o docente transforme a realidade mediante a práxis.

Destacou-se o autor Bernard Charlot, que influenciou Franco por meio do livro Les sciences de l'éducation: un enjeu, un défi ${ }^{2}$, "[...] em que discute a questão epistemológica das ciências da educação, da Pedagogia e mesmo da Didática em diferentes países e circunstâncias [...]" (FRANCO, 2012, p. 118, grifo nosso). A teoria da relação com o saber de Charlot é uma forma de questionar quais condições produzem fracasso escolar, qual caminho é preciso tomar para dialogar com elas, como ser produtivo com as crianças tendo como base suas relações com o saber e como selecionar dispositivos pedagógicos para lidar com as situações atuais.

O essencial dos pensamentos de Philippe Meirieu incorporado no texto de Franco (2012), que contribui com o conceito de Didática adotado pela autora, diz respeito à ideia de que a prática pedagógica necessita de planejamento e organização. Franco (2012) retoma em outra parte, mais adiante no livro, a relação entre a Didática, a aprendizagem e o planejamento, o que evidencia que ela

\footnotetext{
2 Em português, "Ciências da educação: uma aposta, um desafio" (tradução nossa).
} 
estabeleceu essas conexões utilizando o "essencial" dos pensamentos de Meirieu e também dos outros pedagogos.

\subsection{Temáticas práticas educativas, pedagógicas e docentes}

No capítulo 3 do livro, intitulado "Práticas pedagógicas nas múltiplas redes educativas", após selecionar as principais ideias e pressupostos de outros pensadores e pedagogos, Franco (2012) direciona o texto para as discussões sobre as práticas educativas, práticas pedagógicas e práticas docentes, procurando diferenciá-las. Em um primeiro momento, pode parecer que estas práticas são apenas sinônimos, porém há aproximações e distanciamentos entre elas. As práticas educativas são apresentadas como práticas que consolidam os processos educativos. A autora do manual esclarece que:

É comum considerar que práticas pedagógicas e práticas educativas sejam termos sinônimos e, portanto, constituam práticas univocas. No entanto, ao falarmos de práticas educativas, estamos referindo-nos a práticas que ocorrem para a concretização de processos educacionais. (FRANCO, 2012, p. 152, grifo nosso).

As práticas educativas e as práticas pedagógicas aproximam-se na sua relação com as práticas sociais e distanciam-se quanto à sua finalidade. Uma prática social torna-se prática educativa quando adquire intencionalidade e objetivos explícitos, podendo ocorrer dentro e fora da instituição escolar, sempre com o propósito de educar (FRANCO, 2012).

As práticas pedagógicas, por sua vez, são aquelas que consolidam processos pedagógicos. Elas possuem cinco características: i) relacionam-se com a cultura escolar e influenciam a cultura social; ii) envolvem ações coletivas negociadas ou impostas; iii) possuem intencionalidade, explícita ou não; iv) são um indicador das particularidades que qualificam os processos educacionais de uma sociedade; $v$ ) permeiam as práticas docentes (FRANCO, 2012).

Sobre as práticas docentes, são aquelas relacionadas às ações dos professores. Para Franco (2012), quando estas práticas não estão alinhadas com a esfera pedagógica, elas perdem a reflexividade, o que reforça a ideia de que as práticas docentes são meras reproduções. Isto implica a concepção de que tais práticas não necessitam de muito investimento para se concretizarem. A respeito disso, a autora aponta que 
O distanciamento entre as esferas pedagógica e educativa reforça a concepção de que a prática docente se realiza na eficiente reprodução de ações mecânicas, pouco embasadas pela reflexão, e assim pode ser considerada como uma tarefa simples, passível de ser construída com poucos recursos. (FRANCO, 2012, p. 167-8).

Porém, não se entregando ao conformismo, a autora ressalta que "[...] não é da natureza das práticas docentes se encontrarem avulsas, desconectadas de um todo, sem o fundamento das práticas pedagógicas que lhe dão sentido e direção" (FRANCO, 2012, p. 163). Em outras palavras, as práticas docentes precisam estar conectadas às práticas pedagógicas para que adquiram sentido e intencionalidade explícitos.

\subsection{Temáticas Subjetividade Pedagógica e Dialogicidade}

A temática subjetividade pedagógica relaciona-se com o pensamento pedagógico e consiste no modo como "[...] a história, a teoria e as práticas pedagógicas estão sendo interpretadas por seus protagonistas" (FRANCO, 2012, p. 142). A autora esclarece que a subjetividade pedagógica foi o instrumento através do qual ela buscou alcançar o objetivo do livro de compreender o sentido da Pedagogia.

No livro, a Pedagogia é reconhecida como ciência que fundamenta e dialoga com a prática docente, como aponta este trecho: "Falo da Pedagogia como ciência, de seu sentido construído historicamente, das teorias e práticas pedagógicas" (FRANCO, 2012, p. 30, grifo nosso). Estas duas perspectivas de Pedagogia (como prática social e ciência) aparecem ao longo do manual, revelando-se uma temática importante para o desenvolvimento das ideias da autora.

Ao tratar do tema subjetividade pedagógica, a autora afirma que é possível interpretar e correlacionar as teorias com as práticas pedagógicas. Para fundamentar a prática pedagógica, a autora buscou os pensamentos e ideias difundidos pelos pensadores clássicos, como Sócrates, Comenius, Rousseau, Pestalozzi, Dewey; e pelos pensadores contemporâneos, tais como Saviani, Libâneo, Pimenta, Bernard Charlot e Philippe Meirieu. No manual, Franco (2012) chegou a estes pensadores e pedagogos através de uma pesquisa junto a professores de Didática, os quais revelaram quais foram suas leituras na formação inicial e para o preparo das aulas.

Outro tema relevante para entender a prática pedagógica é a dialogicidade, muito atrelada à subjetividade pedagógica, pois está presente em toda a extensão 
da obra e aparece em todos os pensadores selecionados por Franco (2012). Logo no início do primeiro capítulo, a temática surge quando a autora discorre sobre a importância da maiêutica, a arte dialogal de Sócrates. A maiêutica é apresentada como um método "pedagógico". Em nota, Franco (2012) explica que o termo está entre aspas, pois

[...] na realidade, a Pedagogia não se havia instituído nessa época. O trabalho de Sócrates era educativo e não pedagógico. Sua intenção era individual, não institucionalizada; não havia pretensão de continuidade em sua ação. (FRANCO, 2012, p. 45).

A autora reinterpretou pedagogicamente o princípio do diálogo de Sócrates, amparando-se na subjetividade pedagógica para justificar sua interpretação e releitura. Posteriormente, é possível perceber a intenção de Franco (2012) no sentido de fundamentar as práticas pedagógicas no princípio da dialogicidade, pois destaca que esse "[...] princípio será retomado por muitos pedagogos, mas especialmente por Paulo Freire" (FRANCO, 2012, p. 46). No decorrer do livro, este pensador brasileiro é atrelado historicamente a outros educadores e pedagogos, o que demonstra a afinidade de Franco (2012) com as teorias pedagógicas críticas de Freire.

\section{5 $O$ encaminhamento metodológico proposto no manual: a pesquisa-ação}

No manual em estudo, a pesquisa-ação é proposta como encaminhamento metodológico. Em seu caráter praxeológico, a pesquisa-ação é uma metodologia de pesquisa e processo pedagógico que promove a construção de dinâmicas no coletivo, a reflexão, a produção de saberes e a socialização de saberes, assim como a análise e avaliação da própria prática (FRANCO, 2012).

A autora acredita que apenas a pesquisa-ação é capaz de investigar as práticas docentes e aponta as limitações da pesquisa científica em coletar dados consistentes e significativos junto aos professores. Franco aposta neste encaminhamento metodológico como atividade investigativa e prática que pode ajudar os docentes a romperem com práticas cauterizadas e os pesquisadores a coletarem dados mais relevantes, como evidenciado no seguinte trecho:

Considero que a pesquisa-ação pode ser instrumento para potencializar o trabalho dos pesquisadores, permitindo-Ihes produzir conhecimentos mais articuladores para a prática docente, ao mesmo tempo em que oferece aos 
docentes a oportunidade de tornarem-se pesquisadores da própria prática. (FRANCO, 2012, p. 212, grifo nosso).

Para ser efetiva, a pesquisa-ação precisa atender três condições prévias. Primeiramente, esta metodologia de pesquisa possui a especificidade de transformar os sujeitos da prática em um processo contínuo, coletivo, compartilhado e demorado, não consistindo na mera coleta de dados em pesquisa de campo ou na aplicação de metodologia alternativa de aula (FRANCO, 2012).

A segunda condição é a produção diferenciada de saberes e conhecimentos. Para a autora do manual, o pesquisador principal e os sujeitos da prática (os docentes) se apropriam diferenciadamente da realidade, em função dos papéis que adquirem durante o processo da pesquisa-ação (FRANCO, 2012) .

A última condição diz respeito aos tempos da pesquisa-ação, isto é, à simultaneidade entre a pesquisa científica e a prática docente. Ambas ocorrem ao mesmo tempo, porém em níveis e velocidades distintas, assim como com implicações diferentes para a perspectiva dos docentes e do pesquisador principal (FRANCO, 2012).

A pesquisa-ação é estruturada em cinco processos pedagógicos: construção da dinâmica do coletivo; ressignificação das espirais reflexivas; redireção e avaliação das práticas; produção de conhecimento e socialização dos saberes; e conscientização das novas dinâmicas compreensivas. A construção da dinâmica do coletivo refere-se à inserção do pesquisador principal na escola. Busca mobilizar a cooperação profissional e o planejamento coletivo das ações, denominado de contrato de trabalho coletivo (FRANCO, 2012).

As espirais reflexivas para a autora dizem respeito à reflexão contínua sobre a prática com o intuito de formar um professor crítico-reflexivo capaz de ressignificar suas percepções acerca da realidade que o rodeia. Como parte das espirais reflexivas, encontra-se a avaliação das práticas. A avaliação deve estar referenciada na reflexividade contextualizada nos fundamentos éticos e políticos do meio social (FRANCO, 2012).

A autora explora também a produção diferenciada de conhecimentos e saberes como um momento pedagógico da pesquisa-ação. No livro, os conhecimentos são os dados coletados, analisados e contextualizados durante a investigação. Já os saberes são os conhecimentos que visam a ações emancipatórias e transformadoras da realidade dos sujeitos (FRANCO, 2012). Segundo a autora, o 
momento da transformação das práticas dos docentes é denominado de novas dinâmicas compreensivas, e a mudança não ocorre somente nas práticas, mas nos próprios sujeitos, através do autoconhecimento.

A pesquisa-ação visa à ação coletiva, à reflexividade, ao planejamento e a ações que transformem a sociedade (FRANCO, 2012). Conforme a autora, é preciso "[...] tornar o professor capaz de melhor compreender sua prática e assim poder transformá-la [...], num movimento que denomino [...] professor pesquisador" (FRANCO, 2012, p. 183). Neste sentido, a pesquisa-ação é proposta como metodologia de pesquisa e instrumento inerentes à prática docente, atuando como mediadora entre as práticas pedagógicas e docentes.

\section{CONSIDERAÇÕES FINAIS}

Pode-se afirmar a partir desta pesquisa, cujo foco foi a análise do manual/ livro "Pedagogia e Prática Docente" (2012), que há atualmente, nos livros voltados para professores, uma variedade de temas da Pedagogia e Didática que se tornaram referências às práticas docentes e escolares. A pesquisa colabora para o fortalecimento da produção do conhecimento no campo de estudo da formação docente e, assim, para pensar o Curso de Pedagogia enquanto importante espaço para formação profissional. Estudos sobre a Pedagogia como ciência pedagógica e disciplina escolar podem trazer novos elementos para se pensar a identidade de pedagogos orientada por uma perspectiva plural, formativa e emancipatória. Como ciência da educação, a Pedagogia pode ser considerada um instrumento reflexivo, crítico, político e de emancipação dos sujeitos.

A pesquisa ora apresentada contribui também com os estudos que tenham como foco a análise de livros e leituras para a formação de professores. Não se pode negar a potencialidade das pesquisas voltadas à análise de manuais pedagógicos, pois estes têm elementos que permitem entender o projeto de formação de professores implementados em determinados períodos históricos. Assim, buscou-se evidenciar quais têm sido os conhecimentos pedagógicos tratados quando o tema é a Pedagogia e a docência.

Admite-se, portanto, que o livro analisado cumpre o propósito da Coleção Docência em Formação, que é interferir na realidade educacional por meio do processo de aprendizagem, pois afirma que a docência é um campo específico de 
intervenção profissional na prática social, devendo ser reconhecida e valorizada no meio educacional.

A análise do manual "Pedagogia e Prática Docente" permitiu identificar os conteúdos pedagógicos que compõem o livro. Na pesquisa, foram analisadas sete temáticas, que são: Pedagogia, Didática, Prática Docente, Práticas Educativas, Práticas Pedagógicas, Subjetividade Pedagógica e Dialogicidade. Além das temáticas, foi possível descrever a pesquisa-ação como encaminhamento metodológico.

No manual/livro, a autora procurou fundamentar todos esses conhecimentos pedagógicos com referenciais teóricos, interligando-os ao longo do livro para construir sua tese de que a pedagogia como ciência pode embasar as práticas docentes. Essa fundamentação teórica caracteriza o livro como manual pedagógico que se propõe a ser referencial para as práticas docentes.

A pedagogia é defendida como uma ciência que fundamenta e dialoga com a prática docente. É uma prática social que organiza a educação em relação aos seus tempos e espaços, contribuindo, assim, com a reflexão contínua sobre o papel docente e as finalidades e metodologias mais adequadas. A reflexão sobre as práticas pedagógicas permite compreender e transformar as práticas educativas, de forma que atinjam as finalidades estabelecidas em cada momento histórico.

Concorda-se com a autora quando afirma que o docente tem um papel muito importante no processo de fundamentar pedagogicamente suas práticas, pois isto apenas ocorre se ele se conscientiza de que suas ações interferem e são interferidas pelo coletivo da escola, e que seu trabalho pode ter significado na vida dos seus alunos (FRANCO, 2012).

Além das temáticas, outro tema relevante apresentado no manual é a pesquisa-ação, apresentada no livro como instrumento capaz de interligar a Pedagogia e a prática docente. A pesquisa-ação também é abordada como metodologia de pesquisa e prática pedagógica com potencial para transformar os saberes e o contexto profissional dos professores. A autora realça que a pesquisa-ação é uma alternativa metodológica e prática pedagógica, que tem como objetivo a produção de conhecimentos educacionais e a formação de "[...] sujeitos pesquisadores, críticos e reflexivos" (FRANCO, 2012, p. 203).

Estes resultados permitem concluir que o manual "Pedagogia e Prática Docente" possui conhecimentos pedagógicos que contribuem com as discussões no campo da Pedagogia, Didática e Formação Docente. O manual é constituído de 
rica fundamentação teórica e propõe uma metodologia de pesquisa-ação como alternativa às ações dos professores. O campo pedagógico está marcado pelo diálogo e pluralidade de enfoques, reflexão e pesquisa.

É evidente a presença em pesquisas atuais e orientações curriculares de autores da Pedagogia Contemporânea, como Saviani, Libâneo, Pimenta, Bernard Charlot, Philippe Meirieu e Paulo Freire. Mas, ao mesmo tempo, a análise mostra que a Pedagogia Contemporânea mantém o diálogo com a Pedagogia Clássica, tendo como matriz as ideias de autores como Sócrates, Comenius, Rousseau, Pestalozzi e Dewey.

Conclui-se que é necessário continuar aprofundando estudos sobre os conhecimentos pedagógicos na formação de professores e nos manuais nesses últimos anos, pois eles são fonte de novas leituras que podem orientar os docentes em seu processo formativo e, assim, contribuir com as pesquisas na área pedagógica e no enfrentamento dos desafios postos na formação de professores na atualidade.

\section{REFERÊNCIAS}

BARDIN, L. Análise de conteúdo. Tradução de Luis Antero Reto e Augusto Pinheiro. São Paulo: Edições 70, 2011. [Título original: L'analyse de contenu].

BUFREM, L. S.; SCHMIDT, M. A.; GARCIA, T. M. F. B. Os manuais destinados a professores como fontes para a história das formas de ensinar. Revista HISTEDBR On-line, Campinas, n. 22, p. 120-30, jun. 2006. Disponível em: https://www.fe.unicamp.br/pf-fe/ publicacao/4900/art09_22.pdf. Acesso em: 30 set. 2021.

CHARTIER, R. O mundo como representação. Revista Estudos avançados, São Paulo, v. 5, n. 11, p. 173-91, abr. 1991. Disponível em: http://www.scielo.br/scielo.php?script=sci_ arttext\&pid=S0103-40141991000100010\&lng=en\&nrm=iso. Acesso em: 18 fev. 2020.

CHOPPIN, A. História dos livros e das edições didáticas: sobre o estado da arte. Rev. Educação e Pesquisa, São Paulo, v. 30, n. 3, p. 549-66, set./dez. 2004.

FRANCO, M. A. R. S. Pedagogia e prática docente. São Paulo: Editora Cortez, 2012. (Coleção Docência em Formação: Série Saberes Pedagógicos, coordenação de Selma Garrido Pimenta).

GARCIA, T. M. B; SILVA, V. B. De como ensinar: traços paradigmáticos nos manuais pedagógicos e perspectivas de investigação (1870-2015). Educar em Revista, Curitiba, 
v. 35 , n. 77, p. 135-58, out. 2019. Disponível em: http://www.scielo.br/scielo. php?script=sci_arttext\&pid=S0104-40602019000500135\&lng=en\&nrm=iso. Acesso em: 11 maio 2021.

LÜDKE, M.; ANDRÉ, M. E. D. A. Pesquisa em educação: abordagens qualitativas. 2. ed. Rio de Janeiro: E. P. U., 2013.

PIMENTA, S. G. Apresentação da coleção. In: FRANCO, M. A. R. S. Pedagogia e prática docente. São Paulo: Editora Cortez, 2012. p. 11-20. (Coleção Docência em Formação: Série Saberes Pedagógicos, coordenação de Selma Garrido Pimenta).

SILVA, V. B. Uma história das leituras para professores: análise da produção e circulação de saberes especializados nos manuais pedagógicos (1930-1971). Revista Brasileira de História da Educação, [s.l.], v. 3, n. 6, p. 29-57, jul./dez. 2003. Disponível em: http:// periodicos.uem.br/ojs/index.php/rbhe/article/view/38695/20224. Acesso em: 10 dez. 2019.

SILVA, V. B.; CATANI, D. B. Metáforas e comparações que ensinam a ensinar: a razão e a identidade da pedagogia nos manuais para professores (1873-1909). Revista História da Educação, Santa Maria, v. 23, e93223, 2019. Disponível em: http://www.scielo.br/scielo. php?script=sci_arttext\&pid=S2236-34592019000100448\&lng=en\&nrm=iso. Acesso em: 11 maio 2021.

SCHÖN, D. Formar professores como profissionais reflexivos. In: NÓVOA, A. (Org.). Os professores e a sua formação. Lisboa: Dom Quixote, 1992. 158 p.

VALDEMARIN, V. T. Manuais didáticos para uso de professores: mudanças e permanências nas prescrições para a prática pedagógica. In: CONGRESSO BRASILEIRO DE HISTÓRIA DA EDUCAÇÃO, 4., 2006, Goiânia. Anais [...]. Goiânia: UCG, 2006. Disponível em: http:// www.sbhe.org.br/novo/congressos/cbhe4/coordenadas/eixo01/Coordenada\%20por\%20 Dermeval\%20Saviani/Vera\%20Teresa\%20Valdemarin\%20-\%20Texto.pdf. Acesso em: 10 dez. 2019.

\section{Sobre os autores:}

Léia de Cassia Fernandes Hegeto: Doutora em Educação pela Universidade Federal do Paraná (UFPR), na linha de Cultura, Escola e Ensino. Mestre em Educação e graduada em Pedagogia pela Universidade Estadual de Maringá (UEM). Professora adjunta A no curso de Pedagogia da Universidade Federal do Paraná (UFPR). Tem experiência como professora no Ensino Superior na área de Educação, atuando 
com as temáticas: Didática, Didática no Ensino Superior, Formação de Professores, Livros Didáticos, Estrutura e Funcionamento da Educação, Organização do Trabalho Pedagógico, Gestão Escolar, Planejamento, Políticas Educacionais, Currículo e Fundamentos da Educação. Atua no Grupo de Pesquisa - Observatório de Culturas e Processos Políticos-Pedagógicos (OCUPP-UFPR). E-mail: leiahegeto@hotmail. com, Orcid: http://orcid.org/0000-0002-1388-9561

Tiago Cordeiro dos Reis: Graduando em Licenciatura em Química na Universidade Federal do Paraná (UFPR). Pesquisador voluntário em Projeto de Extensão Universitária e Projeto de Iniciação Científica da UFPR. Tem experiência como docente na área de Educação. E-mail: tiago.cordeiro.reis@gmail.com, Orcid: http://orcid.org/0000-0002-6747-891X

\section{Recebido em: 19/02/2020}

Aprovado em: 12/05/2021 
